Clinical Research Paper

\title{
Maintenance treatment of Uracil and Tegafur (UFT) in responders following first-line fluorouracil-based chemotherapy in metastatic gastric cancer: a randomized phase II study
}

\author{
Wenhua Li ${ }^{1,2}$, Xiaoying Zhao ${ }^{1,2}$, Huijie Wang ${ }^{1,2}$, Xin Liu ${ }^{1,2}$, Xinmin Zhao ${ }^{1,2}$, Mingzhu \\ Huang $^{1,2}$, Lixin Qiu ${ }^{1,2}$, Wen Zhang ${ }^{1,2}$, Zhiyu Chen ${ }^{1,2}$, Weijian Guo ${ }^{1,2}$, Jin Li $^{1,2, *}$ and \\ Xiaodong Zhu ${ }^{1,2}$,* \\ ${ }^{1}$ Department of Medical Oncology, Fudan University Shanghai Cancer Center, Shanghai, China \\ ${ }^{2}$ Department of Oncology, Shanghai Medical College, Fudan University, Shanghai, China \\ * Xiaodong Zhu and Jin Li contributed equally to this work \\ Correspondence to: Xiaodong Zhu, email: xddr001@163.com
}

Jin Li, email: fudanlijin@163.com

Keywords: gastric carcinoma; UFT; chemotherapy; maintenance treatment

Received: October 24, $2016 \quad$ Accepted: December 01,2016 Published: December 12, 2016

Copyright: Li et al. This is an open-access article distributed under the terms of the Creative Commons Attribution License (CC-BY), which permits unrestricted use, distribution, and reproduction in any medium, provided the original author and source are credited.

\section{ABSTRACT}

Background: Maintenance therapy proves to be effective in advanced lung and breast cancer after initial chemotherapy. The purpose of this phase II study was to evaluate the efficacy and safety of Uracil and Tegafur (UFT) maintenance in metastatic gastric cancer patients following the first-line fluorouracil-based chemotherapy.

Methods: Metastatic gastric cancer patients with stable disease or a better response after the completion of first-line chemotherapy were randomized to oral UFT ( $360 \mathrm{mg} / \mathrm{m} 2 \times 2$ weeks) every 3 weeks until disease progression/intolerable toxicity or to observation (OBS). The primary endpoint was progression-free survival (PFS); the secondary endpoints were overall survival (OS) and safety.

Results: The trial was closed after the interim analysis of the 58 enrolled (120 planned) patients. Median PFS was not improved in the UFT group compared with the OBS group ( 3.2 months versus 3.6 months, $P=0.752$ ), as well as the median OS (14.2 months for both, $P=\mathbf{0 . 9 8 3}$ ). However, subgroup analysis showed that low baseline hemoglobin $(<120 \mathrm{~g} / \mathrm{L})$ was associated with poorer PFS with maintenance therapy $(P=0.032)$, while the normal hemoglobin patients benefit from the UFT treatment $(P=0.008)$. Grade 3 to 4 toxicities in the UFT group were anemia $(3.4 \%)$, thrombocytopenia (3.4\%) and diarrhea (6.9\%).

Conclusions: This trial did not show superiority of UFT maintenance in nonselected patients responding to fluorouracil-based first-line chemotherapy. The normal hemoglobin level at baseline is a predictive biomarker for favorable patient subsets from the maintenance treatment.

\section{INTRODUCTION}

Gastric cancer is the third leading cause of cancerrelated death worldwide. Nearly 1 million people in the world are diagnosed with gastric cancer every year, and approximately half of them are in China [1]. Fluorouracil-based regimens, such as ECF (epirubicin, cisplatin and 5-fluorouracil), EOF(epirubicin, oxaliplatin and 5-fluorouracil) and XELOX (oxaliplatin plus capecitabine), have been demonstrated to provide survival benefit to patients with advanced or metastatic gastric cancer $[2,3]$. However, recurrence or disease progression is still the main cause for treatment failure.

The concept of maintenance therapy was raised up for expectation of further improvement in efficacy and reduction on disease progression after the initial treatment. In non-small-cell lung cancer, continuation maintenance 
Table 1: Baseline demographic and clinical characteristics of full analysis set

\begin{tabular}{|c|c|c|}
\hline \multirow[b]{2}{*}{ Characteristic } & \multicolumn{2}{|c|}{ No. $(\%)$} \\
\hline & UFT group $(n=29)$ & OBS group $(n=29)$ \\
\hline \multicolumn{3}{|l|}{ Age, years } \\
\hline Median & 55 & 55 \\
\hline Range & $23-74$ & $26-70$ \\
\hline \multicolumn{3}{|l|}{ Sex } \\
\hline Male & $22(75.9)$ & $19(65.5)$ \\
\hline Female & $7(24.1)$ & $10(34.5)$ \\
\hline \multicolumn{3}{|l|}{ ECOG PS } \\
\hline 0 & $8(27.6)$ & $8(27.6)$ \\
\hline 1 & $20(69)$ & $21(72.4)$ \\
\hline 2 & $1(3.4)$ & 0 \\
\hline \multicolumn{3}{|l|}{ Primary lesion } \\
\hline Gastric & $28(96.6)$ & $29(100)$ \\
\hline Gastroesophageal junction & $1(3.4)$ & 0 \\
\hline Prior gastrectomy & $7(24.1)$ & $8(27.6)$ \\
\hline \multicolumn{3}{|l|}{ No. of metastatic sites } \\
\hline$\leq 2$ & $19(65.5)$ & $14(48.3)$ \\
\hline$>2$ & $10(34.5)$ & $15(51.7)$ \\
\hline Peritoneal metastases & $7(24.1)$ & $13(44.8)$ \\
\hline \multicolumn{3}{|l|}{ Prior chemotherapy regimen } \\
\hline $\mathrm{ECF} / \mathrm{EOF}$ & $28(96.6)$ & $28(96.6)$ \\
\hline FOLFOX/XELOX & $1(3.4)$ & $1(3.4)$ \\
\hline \multicolumn{3}{|c|}{ Efficacy of prior chemotherapy } \\
\hline $\mathrm{PR}$ & $14(48.3)$ & $14(48.3)$ \\
\hline $\mathrm{SD}$ & $15(51.7)$ & $15(51.7)$ \\
\hline \multicolumn{3}{|l|}{ Baseline Hemoglobin } \\
\hline$\geq 80$ and $<120 \mathrm{~g} / \mathrm{L}$ & $17(58.6)$ & $15(51.7)$ \\
\hline$\geq 120 \mathrm{~g} / \mathrm{L}$ & $12(41.4)$ & $14(48.3)$ \\
\hline
\end{tabular}

Abbreviation: ECOG PS, Eastern Cooperative Oncology Group performance status; PR, partial recession; SD, stable disease.

with pemetrexed or gemcitabine was proved to delay progression after the induction therapy with pemetrexed/ gemcitabine plus cisplatin $[4,5]$. Other anti-cancer drugs with low toxicity could also be considered on maintenance treatment, such as the bevacizumab and tyrosine kinase inhibitors (TKIs) [6, 7]. In breast cancer, maintenance chemotherapy improves PFS but not OS [8]. However, whether the mode of maintenance treatment could be feasible in gastric cancer is unknown.

Uracil and Tegafur (UFT) is an oral 5-fluorouracil (5-FU) compound combining tegafur and uracil in a molar ration of 1:4. Tegafur is metabolized to 5-FU in the liver, and uracil inhibits the main metabolizing enzyme of 5-FU, thereby increasing serum concentration of 5-FU. Oral UFT plus leucovorin (LV) was demonstrated to be equivalent in efficacy with $5-\mathrm{FU} / \mathrm{LV}$ in both the adjuvant setting and palliative setting of chemotherapy with the tolerable toxicity $[9,10]$. UFT was also suggested as the maintenance therapy after surgical adjuvant chemotherapy in stage III colon cancer [11]. As an oral tablet, UFT has practical advantage in long-term treatment. UFT was recommended as one of the oral agents in treating advanced gastric cancer in Japan [12, 13]. Thus, our randomized phase II trial was conducted to further confirm the efficacy of UFT as the maintenance therapy in patients with metastatic gastric cancer for whom response to fluorouracil-based chemotherapy in the first-line treatment.

\section{RESULTS}

\section{Patients}

The trial was activated on August 2009. On June 2014, after the enrollment of 58 patients, recruitment was stopped as a consequence of the negative outcome of the interim data analysis. This report is consequently on the basis of the data available from each of the 58 eligible patients as of June 2016.

A total of 58 patients were randomly assigned in the study, with 29 assigned to UFT group and 29 assigned to observation group. The demographics and baseline characteristics of the two arms were well balanced (Table 1). Fifty-four patients received EOF regimen in the firstline chemotherapy. The percentages of patients with more than 2 metastatic sites and peritoneal metastases in the observation group were relatively higher than that in the 
Table 2: Analysis of efficacy in full analysis set

\begin{tabular}{|l|c|c|c|}
\hline & UFT group $(\boldsymbol{n}=\mathbf{2 9})$ & OBS group $(\boldsymbol{n}=\mathbf{2 9})$ & $\boldsymbol{P}$ \\
\hline PFS & & & \\
\hline Disease progression or death, No. & 25 & 26 & \\
\hline Median $(95 \%$ CI), months & $3.2(1.4$ to 5.0$)$ & $3.6(1.7$ to 5.5$)$ & 0.752 \\
\hline OS & & & \\
\hline Death, No. & 19 & 21 & \\
\hline Median $(95 \%$ CI), months & $14.2(11.1$ to 17.3$)$ & $14.2(8.2$ to 20.3$)$ & 0.983 \\
\hline
\end{tabular}

Abbreviations: PFS, progression-free survival; OS, overall survival.

UFT group, respectively $51.7 \%$ versus $34.5 \%$ and $44.8 \%$ versus $24.1 \%$, but there was no statistically significant difference between the two arms $(P=0.18$ and 0.58$)$.

\section{Treatment}

Patients in the UFT group received 6.3 cycles of medication on average (range 1-44). Eight-three percent of patients were treated over two or more cycles, and $34.5 \%$ percent of patients over six or more cycles. There were 6 patients experienced disease progression within one month after the randomization in the UFT group, while there were 4 in the OBS group.

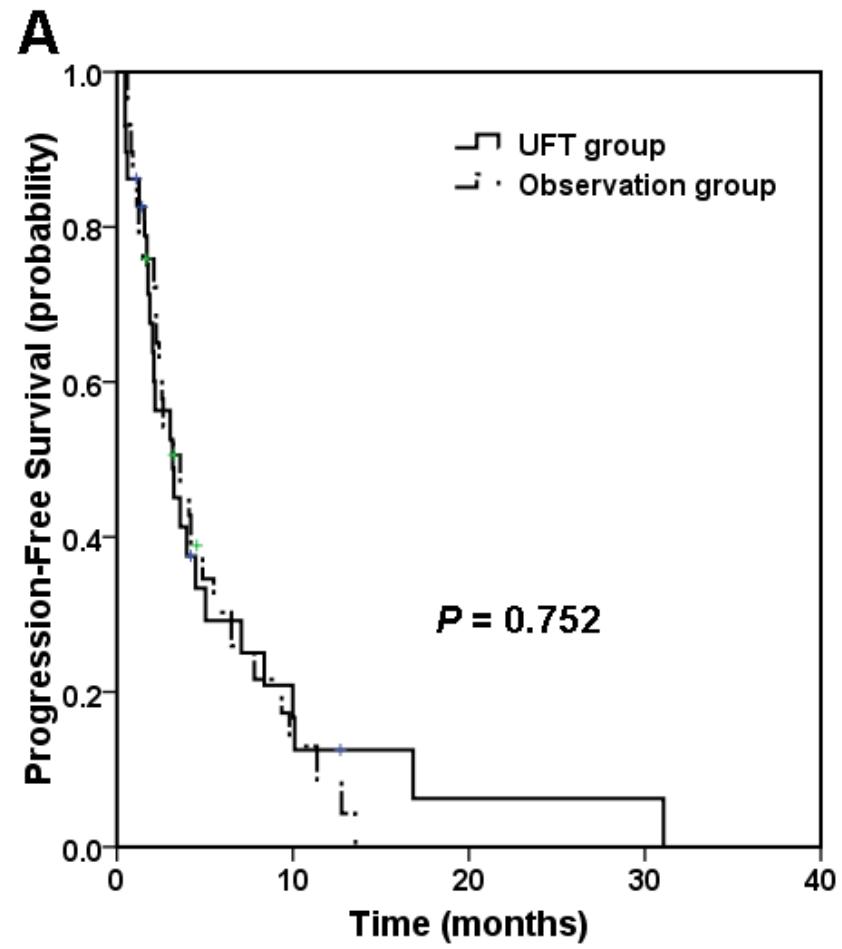

Efficacy

After a median follow-up of 31.3 months (range, 1-57.1 months), 51 patients experienced disease progression, including $25(89.3 \%)$ in the UFT group and $26(89.7 \%)$ in the OBS group. The median PFS was 3.2 months (95\% CI, 1.4-5.0) for the UFT group and 3.6 months $(95 \% \mathrm{CI}, 1.7-5.5)$ for the OBS group. No significant difference was observed between the two groups with the $\mathrm{P}$ value of 0.752 (Table 2, Figure 1A). The median OS was 14.2 months $(95 \% \mathrm{CI}, 11.1-17.3)$ with the UFT group and 14.2 months (95\% CI, 8.2-20.3) with the OBS group ( $P=0.983$, Table 2 , Figure 1B).

Baseline hemoglobin subgroup analysis showed that patients with low hemoglobin $(<120 \mathrm{~g} / \mathrm{L}, n=32)$ had a shorter PFS after the maintenance therapy (1.9 months in

B

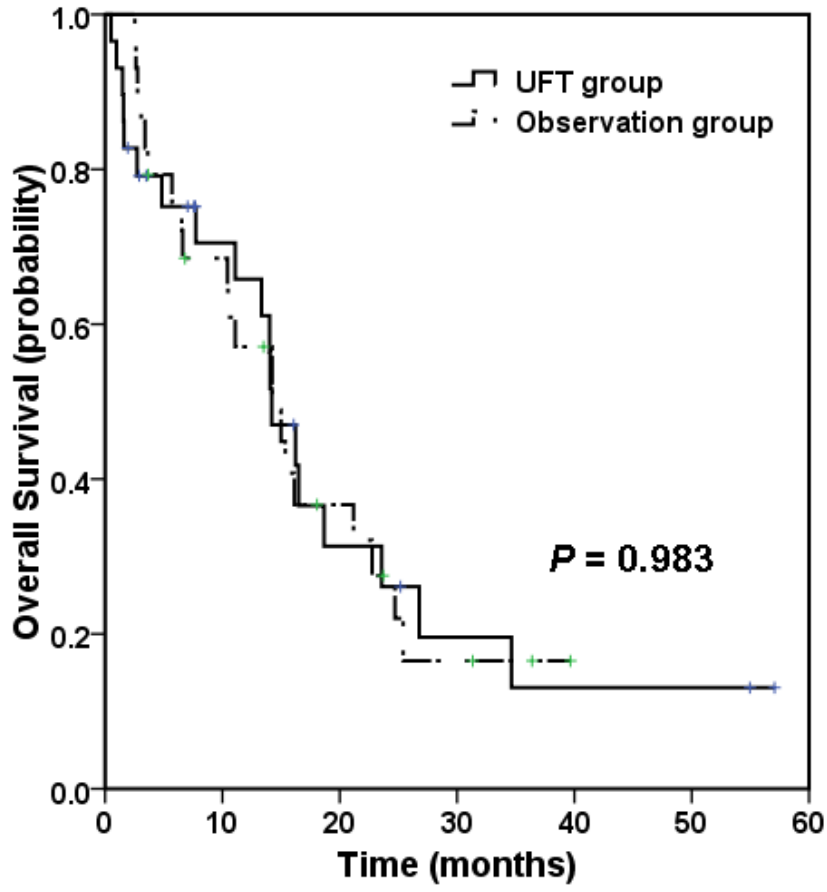

Figure 1: Kaplan-Meier estimates of progression-free survival (PFS) and overall survival (OS). A. Median PFS was 3.2 months in UFT group compared with 3.6 months in observation group. B. Median OS was 14.2 months in both UFT group and observation group. 
Table 3: Analysis of safety in full analysis Set

\begin{tabular}{|l|c|c|c|c|}
\hline & \multicolumn{4}{|c|}{ No. (\%) } \\
\hline Adverse Event & UFT group $(\boldsymbol{n}=\mathbf{2 9})$ & & OBS group $(\boldsymbol{n}=\mathbf{2 9})$ & \\
\hline Hematologic & Any grade & Grade 3 or 4 & Any grade & Grade 3 or 4 \\
\hline Leucopenia & & & & 0 \\
\hline Neutropenia & $7(24.1)$ & 0 & $2(6.9)$ & 0 \\
\hline Anemia & $4(13.8)$ & 0 & $1(3.4)$ & 0 \\
\hline thrombocytopenia & $12(41.4)$ & $1(3.4)$ & $2(6.9)$ & 0 \\
\hline Non-hematologic & $3(10.3)$ & $1(3.4)$ & $1(3.4)$ & 0 \\
\hline Hyperbilirubinemia & $3(10.3)$ & 0 & & 0 \\
\hline Fatigue & $3(10.3)$ & 0 & 0 & 0 \\
\hline Increased ALP & $7(24.1)$ & 0 & 0 & 0 \\
\hline Elevated GGT & $2(6.9)$ & 0 & $1(3.4)$ & 0 \\
\hline Decreased appetite & $6(20.7)$ & 0 & $2(6.9)$ & 0 \\
\hline Diarrhea & $2(6.9)$ & $2(6.9)$ & 0 & 0 \\
\hline Abdominal distension & $4(13.8)$ & 0 & $1(3.4)$ & 0 \\
\hline
\end{tabular}

Abbreviations: ALP, alkaline phosphatase; GGT, $\gamma$-glutamyltransferase

17 patients of UFT group versus 3.6 months in 15 patients of OBS group, $P=0.032$, Figure $2 \mathrm{~A}$ ), whereas patients with normal hemoglobin $(\geq 120 \mathrm{~g} / \mathrm{L}, n=26)$ benefit from the UFT maintenance (7.1 months in 12 patients of UFT group versus 2.4 months in 14 patients of OBS group, $P$ $=0.008$, Figure 2C). Similar trend was also observed in the OS analysis. Patients with normal baseline hemoglobin had a better survival trend after the maintenance therapy (23.6 months versus 10.5 months, $P=0.09$, Figure $2 \mathrm{~B}$ ), whereas patients with low hemoglobin did not (14. 0 months versus 21.2 months, $P=0.106$, Figure 2D).

Stratified with the best efficacy in prior chemotherapy, CR/PR responders $(n=28)$ had no improvement in PFS and OS after the maintenance therapy compared with SD patients $(n=30)$, with a $\mathrm{P}$ value of 0.706 and 0.99 .

\section{Safety}

The most common adverse events with incidences of $10 \%$ or greater in the UFT group were leucopenia, anemia, thrombocytopenia, hyperbilirubinemia, fatigue, increased ALP, decreased appetite and abdominal distension (Table 3 ). Grade 3 to 4 toxicities in the UFT group were anemia, thrombocytopenia and diarrhea. Rare hematologic adverse events and gastrointestinal reaction (less than 10\%) were reported in OBS group. Anemia and increased ALP in any grade occurred more often in the UFT group than in the OBS group (respectively, $41.4 \%$ versus $6.9 \%, P=$ $0.0049 ; 24.1 \%$ versus $0 \%, P=0.01$ ). Grade 3 diarrhea was increased in the UFT group, but this was not significant (6.9\% versus $0 \%, P=0.49)$. Only two patients required dose reduction of UFT because of severe diarrhea.

\section{DISCUSSION}

To our knowledge, this is the first randomized phase II study evaluation of oral fluoropyrimidine maintenance after the first-line fluorouracil-based chemotherapy in metastatic gastric cancer patients. The majority of the patients received 5-day EOF regimen in our previous studies $[14,15]$ and obtained the PR or SD response. Following the consideration of all available information, a decision was taken to close the trial after the enrollment of 58 of the planned 120 patients had been achieved. We did not observe the improvement in PFS and OS with the continuation of UFT after the initial treatment though the safety profile was acceptable.

Although fluorouracil-based three-drug or doubledrug regimens are widely accepted as the first-line treatment for advanced gastric cancer [2, 3], it remains to be determined whether the maintenance therapy should be administered or not. The concept of chemotherapy administration till the development of progressive disease is still widely accepted though there is no direct evidence obtained from randomized controlled study. But it is not tolerated for the advanced gastric cancer patients to receive more than 6-8 cycles of the combination therapy due to the cumulated toxicity or deteriorated performance status. Therefore, continuation of fluorouracil is an option both in clinical practice and in international phase III studies, such as the EXPAND study [16] and AVAGAST study [17]. Capecitabine and/or targeted agent were designed to be continued until disease progression after six-cycle chemotherapy of platinum plus fluorouracil in advance gastric cancer patients [16, 17]. However, our results challenged the fluorouracil maintenance treatment in non-selected patients. Similar finding was also reported in the phase III COIN study in colorectal cancer [18]. No 
improvement in OS was found for all patients with the continuous chemotherapy and survival benefit was only suggested in the subpopulation of patients with higher platelet [18]. These data, including the results of COIN study and ours, showed the importance of suitable patient identification in the application of maintenance treatment.

The striking outcome from the study is the significant correlation of a normal baseline hemoglobin level as a predictive biomarker for the maintenance therapy strategy. Nearly half of the patients in this study had normal hemoglobin level at baseline and these patients

\section{A Low hemoglobin level $(<120 \mathrm{~g} / \mathrm{L})$}

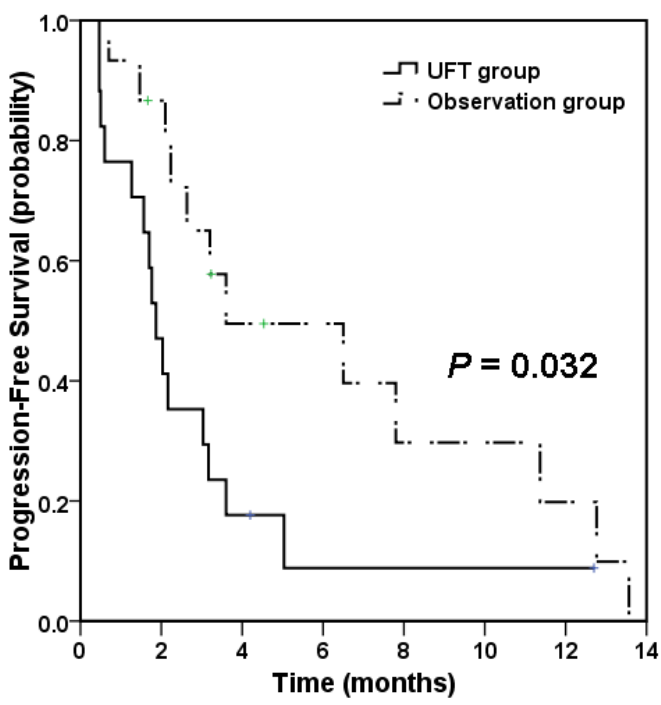

C Normal hemoglobin level $(\geq 120 \mathrm{~g} / \mathrm{L})$

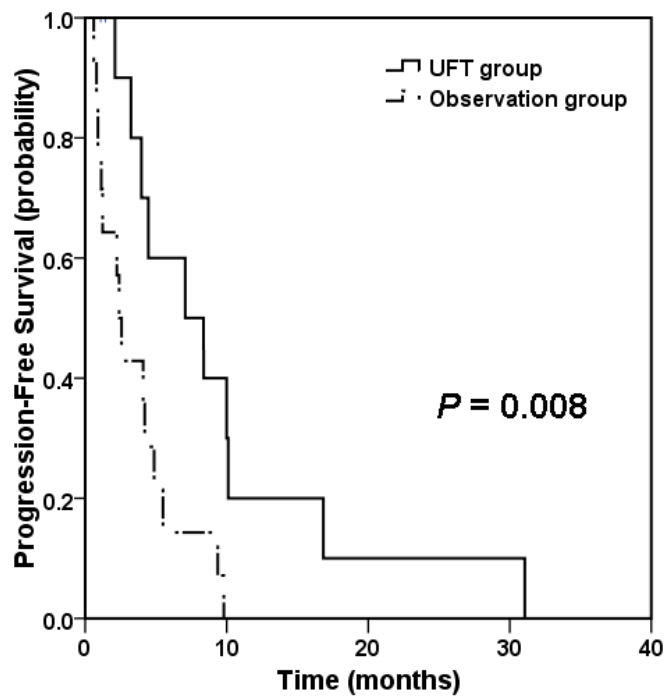

had substantially increased PFS (a 4.7-month increase with a $P$ value of 0.032 ) when treated with UFT, and the survival curve also separated in the analysis of OS with a 13-month increase although the $\mathrm{P}$ value did not reach statistical difference. By contrast, the patients with low hemoglobin level $(80 \sim 120 \mathrm{~g} / \mathrm{L})$ had inferior PFS and no improvement in survival. The hemoglobin level has previously been identified as a predictive and prognostic factor in advanced gastric cancer [19, 20]. And patients with low baseline hemoglobin level rarely benefit from second-line chemotherapy [20]. The mechanism could

\section{B Low hemoglobin level $(<120 \mathrm{~g} / \mathrm{L})$}

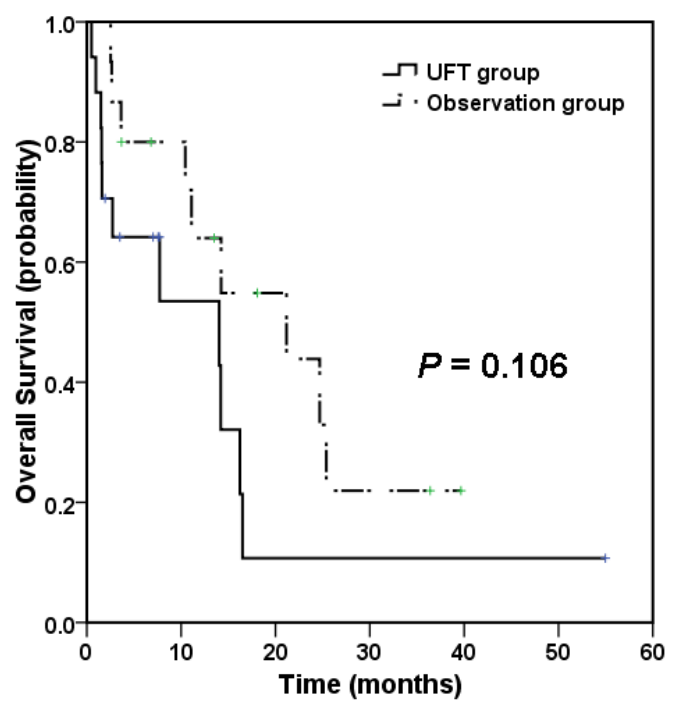

D Normal hemoglobin level $(\geq 120 \mathrm{~g} / \mathrm{L}$ )

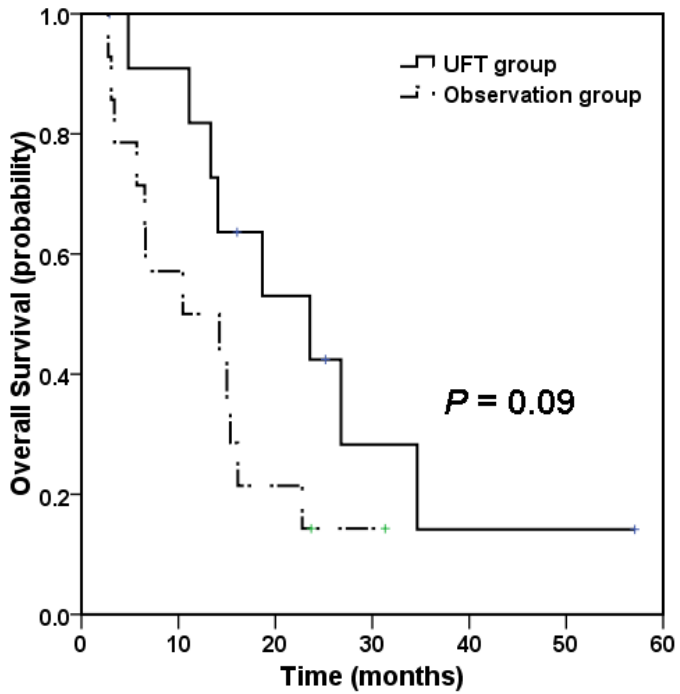

Figure 2: Kaplan-Meier curves of progression-free survival (PFS) and overall survival (OS) by baseline hemoglobin subgroup. In patients with low hemoglobin level $(<120 \mathrm{~g} / \mathrm{L})$, A. median PFS was 1.9 months in UFT group compared with 3.6 months in observation group, and B. median OS was 14.0 months in UFT group compared with 21.2 months in observation group; In patients with normal hemoglobin level ( $\geq 120 \mathrm{~g} / \mathrm{L})$, C. median PFS was 7.1 months in UFT group compared with 2.4 months in observation group, and D. median OS was 23.6 months in UFT group compared with 10.5 months in observation group. 
relate to several reasons, such as the treatment-induced myelosuppression, bleeding, nutritional deficiency and other cytokine-induced chronic disease, all contributing to poor performance status. If confirmed in further randomized phase III study, the easily measurable marker of the hemoglobin level would be a helpful and costeffective predictive biomarker for identification of patients in whom maintenance therapy might be preferable in order to prolong the clinically favorable state.

As the first generation of the oral prodrug of 5-FU, UFT is commonly used in East Asia and many other countries except US [21, 22]. The second generation compounds exhibited stronger antitumor activity [23]. For example, capecitabine is activated preferentially in tumors because of the metabolized enzymes in converting into 5-FU in vivo [24]. And S1 contains 5-chloro-2,4dihydroxypyridine (CDHP, a potent reversible inhibitor of 5-FU degradation) and potassium oxonate (OXO, 5-FU phosphorylation selective inhibitor which distributes much higher in gastrointestinal tract)to potentiate the antitumor activity and decrease the toxicity [25]. Both of these two drugs were proved to be effective in the initial treatment for advanced gastric cancer patients [26-28]. In further study design, both capecitabine and S1 might be the alternative option in the maintenance treatment after the initial 5-FU-based chemotherapy in metastatic gastric cancer.

Safety profile of UFT in this study exhibited that myelotoxicity was mild while the gastrointestinal reaction was the major toxicity, but no hand-foot syndrome was observed. This was consistent with the data in previous trials of UFT in patients with other solid tumors $[7,10$, 29, 30].It may because that the gastrointestinal adverse event, diarrhea for instance, was correlated significantly with the maximum plasma concentration and $\mathrm{AUC}_{0-6 \mathrm{~h}}$ of 5-FU, while the hand-foot syndrome was characteristic to continuous intravenous infusion of 5-FU $[29,31]$. The plasma concentration of 5-FU after oral administration of UFT had wide interpatient and intrapatient variations. The determination of plasma level used to be recommended [31], but it was not routinely taken due to the inconvenience. In our study, the plasma concentration was not accessed and limited data could be shown.

Although the maintenance therapy of UFT did not reach the primary objective in whole population in this trial, it is possible that benefit could be achieved by better selection of patient population and the new agent. The normal hemoglobin level at baseline is a potential biomarker separating patient subsets who do better from the UFT maintenance treatment. Further randomized phase III study may help identify the role of oral fluoropyrimidine by considering the use of capecitabine or S1 in proper patients with normal hemoglobin.

\section{MATERIALS AND METHODS}

\section{Patients}

Patients aged 18-75 years with histologically or cytologically confirmed metastatic gastric adenocarcinoma received first-line chemotherapy with fluorouracil-based regimen (ECF/EOF or FOLFOX/XELOX regimen, 3-week regimen for 6 cycles and 2-week regimen for 12 cycles). Patients with stable disease or a better response with an Eastern Cooperative Oncology Group performance status (ECOG PS) of 0 to 2 and life expectancy of $\geq 3$ months were eligible. Patients were required to have adequate bone marrow (neutrophil $\geq 1.5 \times 10^{9} / \mathrm{L}$, hemoglobin $\geq 80 \mathrm{~g} / \mathrm{L}$, platelet $\left.\geq 75 \times 10^{9} / \mathrm{L}\right)$, hepatic, and renal function. Patients with brain or meninges metastases, bowel obstruction, symptomatic peripheral neuropathy, severe cardiac disease or uncontrolled infection were excluded. The study was approved by the independent ethics committee of Fudan University Shanghai Cancer Center, Shanghai, China (Approval number IRB 09087512) and registered at ClinicalTrials.gov (NCT02903498). The study was carried out in accordance with the Declaration of Helsinki. All patients provided written informed consent before study entry.

\section{Treatment}

All enrolled patients were randomly assigned at a 1:1 ratio to receive either oral UFT or just observation (OBS), stratified by the best efficacy of the prior chemotherapy $(\mathrm{CR}+\mathrm{PR} / \mathrm{SD})$. Patients received oral UFT $(360 \mathrm{mg} / \mathrm{m} 2$ $\times 2$ weeks) every 3 weeks until disease progression or unacceptable toxicity, or consent withdrawal. The daily doses of UFT were divided into three doses administered 8 hours apart and taken together along with water. Patients were instructed to avoid food consumption between 1 hour before and 1 hour after each dose.

The primary endpoint was progression-free survival (PFS); the secondary endpoints were overall survival (OS) and safety. PFS was defined as the duration from the time of random assignment to the time of disease progression or death whichever occurred first or censored at the last follow-up visit.

\section{Dose modification}

Dose adjustments were made based on the worst grade of toxicity encountered during the previous cycle. For hematological toxicities, the dose of chemotherapeutic drugs was reduced in the following cases: grade 4 neutropenia or leukopenia; grade 3 or greater febrile neutropenia; grade 3 or greater thrombocytopenia. 
For nonhematological toxicity, the dose was reduced when grade 3 or greater toxicities occurred (except for alopecia). The dose was reduced by $25 \%$ of the starting dose. If a patient required more than three successive dose reductions, therapy was discontinued.

Treatment was delayed until the absolute neutrophil count was $\geq 1.5 \times 10^{9} / \mathrm{L}$ and platelet count was $\geq 75 \times 10^{9} / \mathrm{L}$, and recovery to grade $\leq 1$ for nonhematological toxicities (with exception of alopecia).The maximum authorized delay is of 2 weeks.

\section{Assessments}

Pretreatment assessment included a detailed medical history, physical examination, routine laboratory tests, and performance status. Laboratory evaluation included a routine blood count, urinalysis, and electrolyte, renal, and liver function tests.

Radiographic scans (computed tomography or magnetic resonance imaging) for efficacy evaluation were conducted at baseline and every 6 weeks thereafter according to the RECIST 1.0 guidelines. The best overall response was reported. Survival status was assessed every 3 months after discontinuation of study treatment.

Adverse events and concomitant medications were recorded at the end of each cycle. Toxicity was evaluated and graded according to the National Cancer Institute Common Terminology Criteria for Adverse Events, version 3.0 .

\section{Statistical analysis}

This phase II study was designed to assess the improvement of PFS with maintenance UFT. We supposed that the UFT maintenance could improve the median PFS from 1.25 months to 3 months, compared with the observation group. Then, 120 patients (60 patients in each group) were needed with an exact significance level of $p$ $=0.05$ and a power of $90 \%$, considering $10 \%$ drop-off.

Quantitative variables were compared between groups using two-sample $t$ test or Wilcoxon rank sum test. Pearson Chi-square test or Fisher's exact test was used to analyze categorical variables, whenever appropriate. Survival function of time-to-event end points was estimated by using the Kaplan-Meier method. The log-rank test was used for comparisons of PFS and OS between the two groups. All statistical analyses were twosided. The statistical significance level was set at .05 . The CI was set at $95 \%$. All statistical analyses were performed using SPSS software (version 18.0).

\section{Abbreviations}

UFT: Uracil and tegafur; PFS: progression-free survival; OS: overall survival; ECF: epirubicin, cisplatin and continuous infusion of 5-fluorouracil; EOF: epirubicin, oxaliplatin and continuous infusion of 5-fluorouracil; EOX: epirubicin, oxaliplatin and capecitabine; FOLFOX: oxaliplatin, leucovorin and continuous infusion of 5-fluorouracil; XELOX: capecitabine and oxaliplatin; TKIs: tyrosine kinase inhibitors; 5-FU: 5-fluorouracil; ECOG PS: Eastern Cooperative Oncology Group Performance Status; OBS: observation; RECIST: Response Evaluation Criteria in Solid Tumors; CR: complete response; PR: partial response; SD: stable disease; ALP: alkaline phosphatase; CDHP: 5-chloro-2,4dihydroxypyridine; OXO: potassium oxonate.

\section{ACKNOWLEDGMENTS}

We thank all the investigators and enrolled patients for our study.

\section{CONFLICTS OF INTEREST}

The authors declare that they have no competing interests.

\section{FUNDING}

The study was supported by the Foundation of the Shanghai Municipal Science and Technology Commission (Grant No.134119a8600).

\section{Authors' contributions}

Wenhua Li participated in acquisition of data, analysis and interpretation of data, and drafting of the manuscript. Wenhua Li, Xiaoying Zhao, Huijie Wang, Xin Liu, Xinmin Zhao, Mingzhu Huang, Lixin Qiu, Wen Zhang, Zhiyu Chen, Weijian Guo, Jin Li, Xiaodong Zhu carried out the study during clinical observation, follow up, collected the clinical data for analysis. Xiaodong Zhu and Jin Li conceived of the study, participated in its design and coordination and revised the final manuscript. All authors have read and approved the final manuscript.

\section{Trial registration}

ClinicalTrials.gov:NCT02903498.

\section{REFERENCES}

1. Siegel R, Ma J, Zou Z, Jemal A. Cancer statistics, 2014. CA Cancer J Clin. 2014; 64: 9-29. doi: 10.3322/caac.21208. 
2. Cunningham D, Starling N, Rao S, Iveson T, Nicolson M, Coxon F, Middleton G, Daniel F, Oates J, Norman AR. Capecitabine and oxaliplatin for advanced esophagogastric cancer. N Engl J Med. 2008; 358: 36-46. doi: 10.1056/ NEJMoa073149.

3. National Comprehensive Cancer Network: NCCN Clinical Practice Guidelines in Oncology: Gastric Cancer (version 1.2016). https://www.nccn.org/store/login/login. aspx?ReturnURL=https://www.ncen.org/professionals/ physician_gls/pdf/gastric.pdf.

4. Brodowicz T, Krzakowski M, Zwitter M, Tzekova V, Ramlau R, Ghilezan N, Ciuleanu T, Cucevic B, Gyurkovits K, Ulsperger E, Jassem J, Grgic M, Saip P, et al. Cisplatin and gemcitabine first-line chemotherapy followed by maintenance gemcitabine or best supportive care in advanced non-small cell lung cancer: a phase III trial. Lung Cancer. 2006; 52: 155-63. doi: 10.1016/j. lungcan.2006.01.006.

5. Paz-Ares L, de Marinis F, Dediu M, Thomas M, Pujol JL, Bidoli P, Molinier O, Sahoo TP, Laack E, Reck M, Corral J, Melemed S, John W, et al. Maintenance therapy with pemetrexed plus best supportive care versus placebo plus best supportive care after induction therapy with pemetrexed plus cisplatin for advanced non-squamous nonsmall-cell lung cancer (PARAMOUNT): a double-blind, phase 3, randomised controlled trial. Lancet Oncol. 2012; 13: 247-55. doi: 10.1016/S1470-2045(12)70063-3.

6. Cappuzzo F, Ciuleanu T, Stelmakh L, Cicenas S, Szczesna A, Juhasz E, Esteban E, Molinier O, Brugger W, Melezinek I, Klingelschmitt G, Klughammer B, Giaccone G. Erlotinib as maintenance treatment in advanced non-small-cell lung cancer: a multicentre, randomised, placebo-controlled phase 3 study. Lancet Oncol. 2010; 11: 521-9. doi: 10.1016/ S1470-2045(10)70112-1.

7. Patel JD, Hensing TA, Rademaker A, Hart EM, Blum MG, Milton DT, Bonomi PD. Phase II study of pemetrexed and carboplatin plus bevacizumab with maintenance pemetrexed and bevacizumab as first-line therapy for nonsquamous non-small-cell lung cancer. J Clin Oncol. 2009; 27: 3284-9. doi: 10.1200/JCO.2008.20.8181.

8. Muss HB, Case LD, Richards F 2nd, White DR, Cooper MR, Cruz JM, Powell BL, Spurr CL, Capizzi RL. Interrupted versus continuous chemotherapy in patients with metastatic breast cancer. The Piedmont Oncology Association. N Engl J Med. 1991; 325: 1342-8. doi: 10.1056/NEJM199111073251904.

9. Douillard JY, Hoff PM, Skillings JR, Eisenberg P, Davidson N, Harper P, Vincent MD, Lembersky BC, Thompson S, Maniero A, Benner SE. Multicenter phase III study of uracil/tegafur and oral leucovorin versus fluorouracil and leucovorin in patients with previously untreated metastatic colorectal cancer. J Clin Oncol. 2002; 20: 3605-16. doi: 10.1200/JCO.2002.04.123.

10. Lembersky BC, Wieand HS, Petrelli NJ, O'Connell MJ, Colangelo LH, Smith RE, Seay TE, Giguere JK, Marshall
ME, Jacobs AD, Colman LK, Soran A, Yothers G, et al. Oral uracil and tegafur plus leucovorin compared with intravenous fluorouracil and leucovorin in stage II and III carcinoma of the colon: results from National Surgical Adjuvant Breast and Bowel Project Protocol C-06. J Clin Oncol. 2006; 24: 2059-64. doi: 10.1200/JCO.2005.04.7498.

11. Hong KD, Lee SI, Moon HY. The efficacy of oral tegafururacil as maintenance therapy following intravenous 5-fluorouracil chemotherapy in stage III colon cancer. Hepatogastroenterology. 2012; 59: 104-7. doi: 10.5754/ hge10419.

12. Tsuburaya A, Yoshida K, Kobayashi M, Yoshino $\mathrm{S}$, Takahashi M, Takiguchi N, Tanabe K, Takahashi $\mathrm{N}$, Imamura $\mathrm{H}$, Tatsumoto $\mathrm{N}$, Hara A, Nishikawa K, Fukushima R, et al. Sequential paclitaxel followed by tegafur and uracil (UFT) or S-1 versus UFT or S-1 monotherapy as adjuvant chemotherapy for $\mathrm{T} 4 \mathrm{a} / \mathrm{b}$ gastric cancer (SAMIT): a phase 3 factorial randomised controlled trial. Lancet Oncol. 2014; 15: 886-93. doi: 10.1016/S14702045(14)70025-7.

13. Saglam S, Aykan NF, Sakar B, Gulluoglu M, Balik E, Karanlik H. A pilot study evaluating the safety and toxicity of epirubicin, cisplatin, and UFT (ECU regimen) in advanced gastric carcinoma. J Gastrointest Oncol. 2011; 2: 19-26. doi: 10.3978/j.issn.2078-6891.2010.030.

14. Zhu X, Zhao X, Peng W, Sun S, Cao J, Ji D, Liu X, Wang C, Huang M, Yu H, Guo W, Li J, Yin J. Epirubicin combined with oxaliplatin and 5-day continuous infusion of 5-fluorouracil as a first-line treatment for metastatic gastric cancer: treatment outcomes and analysis of prognostic factors. J Cancer Res Clin Oncol. 2015; 141: 109-18. doi: 10.1007/s00432-014-1754-8.

15. Zhu X, Leaw J, Gu W, Qian Y, Du H, Wang B, Hong X, Yin J. Phase II clinical trial of advanced and metastatic gastric cancer based on continuous infusion of 5-fluorouracil combined with epirubicin and oxaliplatin. J Cancer Res Clin Oncol. 2008; 134: 929-36. doi: 10.1007/s00432-008-03764.

16. Lordick F, Kang YK, Chung HC, Salman P, Oh SC, Bodoky G, Kurteva G, Volovat C, Moiseyenko VM, Gorbunova V, Park JO, Sawaki A, Celik I, et al. Capecitabine and cisplatin with or without cetuximab for patients with previously untreated advanced gastric cancer (EXPAND): a randomised, open-label phase 3 trial. Lancet Oncol. 2013; 14: 490-9. doi: 10.1016/S1470-2045(13)70102-5.

17. Ohtsu A, Shah MA, Van Cutsem E, Rha SY, Sawaki A, Park SR, Lim HY, Yamada Y, Wu J, Langer B, Starnawski M, Kang YK. Bevacizumab in combination with chemotherapy as first-line therapy in advanced gastric cancer: a randomized, double-blind, placebo-controlled phase III study. J Clin Oncol. 2011; 29: 3968-76. doi: 10.1200/JCO.2011.36.2236.

18. Adams RA, Meade AM, Seymour MT, Wilson RH, Madi A, Fisher D, Kenny SL, Kay E, Hodgkinson E, Pope M, Rogers $\mathrm{P}$, Wasan $\mathrm{H}$, Falk $\mathrm{S}$, et al. Intermittent versus 
continuous oxaliplatin and fluoropyrimidine combination chemotherapy for first-line treatment of advanced colorectal cancer: results of the randomised phase $3 \mathrm{MRC}$ COIN trial. Lancet Oncol. 2011; 12: 642-53. doi: 10.1016/S14702045(11)70102-4.

19. Park SH, Lee J, Lee SH, Park JO, Kim K, Kim WS, Jung CW, Park YS, Kang WK, Park K, Kim S, Bang SM, Cho $\mathrm{EK}$, et al. Anemia is the strongest prognostic factor for outcomes of 5-fluorouracil-based first-line chemotherapy in patients with advanced gastric cancer. Cancer Chemother Pharmacol. 2006; 57: 91-6. doi: 10.1007/s00280-005-00272.

20. Ji SH, Lim DH, Yi SY, Kim HS, Jun HJ, Kim KH, Chang MH, Park MJ, Uhm JE, Lee J, Park SH, Park JO, Park YS, et al. A retrospective analysis of second-line chemotherapy in patients with advanced gastric cancer. BMC Cancer. 2009; 9: 110. doi: 10.1186/1471-2407-9-110.

21. Malet-Martino M, Martino R. Clinical studies of three oral prodrugs of 5-fluorouracil (capecitabine, UFT, S-1): a review. Oncologist. 2002; 7: 288-323.

22. Fujii S, Kitano S, Ikenaka K, Fukushima M, Nakamura H, Maehara Y, Shirasaka T. Effect of coadministration of thymine or thymidine on the antitumor activity of 1-(2-tetrahydrofuryl)-5-fluorouracil and 5-fluorouracil. Gan. 1980; 71: 100-6.

23. Shirasaka T, Shimamoto Y, Kato T, Fukushima M. [Invention of a tumor-selective 5-fluorouracil derivative named S-1 by biochemical modulation of 5-fluorouracil]. Gan To Kagaku Ryoho. 1998; 25: 371-84.

24. Miwa M, Ura M, Nishida M, Sawada N, Ishikawa T, Mori K, Shimma N, Umeda I, Ishitsuka H. Design of a novel oral fluoropyrimidine carbamate, capecitabine, which generates 5-fluorouracil selectively in tumours by enzymes concentrated in human liver and cancer tissue. Eur J Cancer. 1998; 34: 1274-81.

25. Shirasaka T, Shimamato Y, Ohshimo H, Yamaguchi M, Kato T, Yonekura K, Fukushima M. Development of a novel form of an oral 5-fluorouracil derivative (S-1) directed to the potentiation of the tumor selective cytotoxicity of 5-fluorouracil by two biochemical modulators. Anticancer Drugs. 1996; 7: 548-57.
26. Boku N, Yamamoto S, Fukuda H, Shirao K, Doi T, Sawaki A, Koizumi W, Saito H, Yamaguchi K, Takiuchi H, Nasu J, Ohtsu A. Fluorouracil versus combination of irinotecan plus cisplatin versus S-1 in metastatic gastric cancer: a randomised phase 3 study. Lancet Oncol. 2009; 10: 10639. doi: 10.1016/S1470-2045(09)70259-1.

27. Hong YS, Song SY, Lee SI, Chung HC, Choi SH, Noh SH, Park JN, Han JY, Kang JH, Lee KS, Cho JY. A phase II trial of capecitabine in previously untreated patients with advanced and/or metastatic gastric cancer. Ann Oncol. 2004; 15: 1344-7. doi: 10.1093/annonc/mdh343.

28. Koizumi W, Saigenji K, Ujiie S, Terashima M, Sakata Y, Taguchi T. A pilot phase II study of capecitabine in advanced or recurrent gastric cancer. Oncology. 2003; 64: 232-6. doi: 69313.

29. Pazdur R, Lassere Y, Diaz-Canton E, Ho DH. Phase I trial of uracil-tegafur (UFT) plus oral leucovorin: 28day schedule. Cancer Invest. 1998; 16: 145-51. doi: 10.3109/07357909809050028.

30. Sadahiro S, Suzuki T, Maeda Y, Makuuchi H, Murayama C. [Feasibility of weekday-on/weekend-off oral UFT/Leucovorin schedule as postoperative adjuvant chemotherapy for colorectal cancer]. Gan To Kagaku Ryoho. 2006; 33: 333-6.

31. Ho DH, Covington W, Brown N, Lin SN, Pazdur R, Huo YY, Creaven PJ, Rustum YM, Meropol NJ, Lassere Y, Kuritani J, Hayakawa T. Oral uracil and Ftorafur plus leucovorin: pharmacokinetics and toxicity in patients with metastatic cancer. Cancer Chemother Pharmacol. 2000; 46: 351-6. doi: 10.1007/s002800000156. 